\title{
AA7075 Matrisli B4C+SiC Takviyeli Hibrit Kompozitlerin Toz Takviyeli EEİ Yöntemiyle İşlenmesinde Boşalım Akımı ve Takviye Oranının İşlenmiş Yüzeyin Mikroyapısı ve Pürüzlülüğüne Etkisi
}

\section{The Effect of Discharge Current and Reinforcement Ratio on the Microstructure and Roughness of the Machined Surface in the Machining of AA7075 Matrix B4C+SiC Reinforced Hybrid Composites by Powder Reinforced EDM Method}

\author{
Gözde Keskin $^{1}$ iD , Gökhan Küçüktürk ${ }^{2}$ iD ${ }^{\text {, Muharrem Pul }}{ }^{3}$ iD, Hakan Gürün ${ }^{4}$ iD, Volkan Baydaroğlu $^{5}$ iD \\ ${ }^{I}$ Gazi Üniversitesi, Fen Bilimleri Enstitüsü, Makina Mühendisliği Anabilimdalı, 06500 Ankara, TÜRKIYYE \\ ${ }_{2}$ Gazi Üniversitesi, Mühendislik Fakültesi, Makina Mühendisliği Bölümü,06500 Ankara, TÜRKIYYE \\ ${ }^{3}$ Kırıkkale Üniversitesi,Kırıkkale Meslek Yüksekokulu, Elektrik ve Enerji Bölümü, 71450, Kırıkkale, TÜRKIYYE \\ ${ }^{4}$ Gazi Üniversitesi, Teknoloji Fakültesi, Imalat Mühendisliği Bölümü,06500 Ankara, TÜRKIYE \\ ${ }^{5}$ Botaş Lng İşletme Müdürlüğü, 59760 Tekirdă̆, TÜRKIYYE
}

Başvuru/Received: 26/02/2021Ｋabul/Accepted: 09/03/2021Ｃ̧evrimiçi Basım / Published Online: 23/05/2021

Son Versiyon/Final Version: 18/06/2021

\section{$\ddot{\mathbf{O} z}$}

Bu çalışmada farklı takviye hacim oranlarında üretilmiş olan AA7075 matrisli B4C+SiC takviyeli hibrit kompozitlerin, Toz Katkılı Elektro Erozyon ile İşleme (TKEEI) yöntemiyle işlenmesinde, işleme deşarj akımı ve B4C+SiC takviye oranlarının işlenmiş yüzeylerin mikroyapısına etkisi incelenmiştir. $\% 5 \mathrm{~B} 4 \mathrm{C}+\% 5 \mathrm{SiC}$ ve $\% 10 \mathrm{~B} 4 \mathrm{C}+\% 10 \mathrm{SiC}$ takviye oranlarında toz metalürjisi tekniğiyle üretilmiş olan AA7075 hibrit kompozit numuneler üzerinde, 2A, 4A ve 8A olmak üzere 3 farklı akım değeri uygulanarak işleme deneyleri gerçekleştirilmiştir. Çalışmanın ikinci aşamasında işlenmiş yüzeylerin elektron mikroskobu görüntüleri çekilmiş ayrıca yüzey pürüzlülük ölçümleri yapılmıştır. Deney ve incelemeler sonucunda boşalım akımının artması ve B4C+SiC takviye oranının yükselmesiyle kompozit yapının olumsuz etkilendiği, işlenen yüzeylerin pürüzlülük değerlerinin yükseldiği görülmüştür. Ancak hem yüzeylerin mikro yapısı hem de pürüzlülük değerleri üzerinde, boşalım akımının artmasının etkisi, $\mathrm{B} 4 \mathrm{C}+\mathrm{SiC}$ takviye oranı artışının etkisinden daha fazla olmuştur.

Anahtar Kelimeler

“AA7075/B4C+SiC Kompozit, Elktro Erozyon İsleme, Boșalım Akımı, Mikro Yapı, Yüzey Pürüzlülüğüu”

\begin{abstract}
In this study, the effect of electro discharge machining and $\mathrm{B} 4 \mathrm{C}+\mathrm{SiC}$ reinforcement ratios on the microstructure of the machined surfaces in the machining of AA7075 matrix $\mathrm{B} 4 \mathrm{C}+\mathrm{SiC}$ reinforced hybrid composites with powder-mixed electro discharge machining (EDM) method was investigated. Machining experiments were carried out on AA7075 hybrid composite samples produced with powder metallurgy technique at $5 \% \mathrm{~B} 4 \mathrm{C}+5 \% \mathrm{SiC}$ and $10 \% \mathrm{~B} 4 \mathrm{C}+10 \% \mathrm{SiC}$ by applying 3 different discharge currents: $2 \mathrm{~A}, 4 \mathrm{~A}$ and $8 \mathrm{~A}$. In the second stage of the study, scanning electron microscopy images of the machined surfaces were taken and surface roughness measurements were made. As a result of the experiments and investigations, it was observed that the composite structure was negatively affected by the increase in the discharge current and the increase in the $\mathrm{B} 4 \mathrm{C}+\mathrm{SiC}$ reinforcement ratio, and the roughness values of the machined surfaces increased. However, the effect of increasing the discharge current on both the microstructure of the surfaces and the roughness values was more than the effect of the increase in the $\mathrm{B} 4 \mathrm{C}+\mathrm{SiC}$ reinforcement ratio.
\end{abstract}

Key Words

“AA7075/B4C+SiC Composite,, Electro Discharge Machining, Discharge Current, Micro Structure, Surface Roughness" 


\section{Giriş}

Bilim ve teknolojinin hızla ilerlemesiyle, üstün özelliklere sahip mühendislik malzemelerinin kullanımı zorunlu hale gelmiştir. Bununla birlikte, gelişmiş özellikleriyle öne çıkan mühendislik malzemelerinin geleneksel imalat yöntemleriyle işlenmesinde birçok zorluk ile karşılaşılmaktadır. Yüksek boyutsal hassasiyet, karmaşık geometri, üstün yüzey kalitesi, düşük yüzey pürüzlülüğü gerektiren ihtiyaçların ortaya çıkması bu tür taleplerin karşılanmasına yönelik imalat yöntemlerini önemli hale getirmektedir. Günümüzde kompozit malzemeler arasında yaygın olarak kullanılan metal matrisli kompozitlerin (MMK) geleneksel imalat yöntemleriyle işlenmesinde de pek çok güçlük ile karşılaşılmaktadır (Garg et al., 2010; Mardi et al.,2017; Sezen 2018; Karakoç 2017).

MMK malzemelerde matris malzemesi olarak, alüminyum, titanyum, bakır ve magnezyum kullanılabilmektedir. Alüminyum düşük yoğunluk, korozyon direnci ve yüksek mukavemete sahip olması nedeniyle en yaygın olarak kullanılan matris malzemesidir. MMK malzeme sınıflandırmalarından biri olan alüminyum esaslı kompozit malzemelerde takviye elemanı olarak en çok tercih edilen seramik partiküller B4C, $\mathrm{SiC}, \mathrm{Al}_{2} \mathrm{O}_{3}$ ve $\mathrm{Si}_{3} 3 \mathrm{~N}_{4}$ 'dir (Garg et al., 2010; Mardi et al.,2017; Sezen 2018; Karakoç 2017). Sert seramik takviyelerin işlemede oluşturduğu değişken yükler nedeniyle aşırı takım aşınmasına yol açması geleneksel yöntemler ile işlemede istenilen toleransların ve yüzey özelliklerinin elde edilememesine yol açmaktadır. Takım aşınmasının ana sebebi, doğrudan temas nedeniyle takımda termal ve mekanik yük meydana gelmesidir. Böylece aşınma süreci hızlanmakta ve takım ömrü kısalmaktadır (Mardi et al. 2017). Kompozit malzemelerin işlenmesinde sıklıkla karşılaşılan bu tür problemlerin üstesinden gelebilmek için elektro erozyon ile işleme (EEI), lazer ışını ile işleme, aşındırıcı su jeti ile işleme, elektrokimyasal işleme ve ultrasonik işleme gibi geleneksel olmayan imal usulleri yöntemlerine başvurulmaktadır (Mardi et al. 2017).

Yüksek mukavemet, sertlik ve aşınma direncine sahip MMK malzemelerin geleneksel imalat yöntemleri ile işlenmesinin zorlukları nedeniyle bu çalışmada başvurulan geleneksel olmayan yöntemlerden olan EEİ yönteminin toz katkılı uygulanabilirliğinin deneysel olarak incelenmesi hedeflenmiştir. Bu konuda literatürde yer alan bazı çalışmalar mevcuttur (Sidhu et al., 2014; Mohanty et al., 2019; Kolli and Kumar 2015). Kompozit yapının kalitesini etkileyen matris malzemesi ile takviye arasındaki sslanabilirlik seviyesi ve takviye partiküllerinin homojen dağılma durumunun toz katkılı elektro erozyon işleme (TKEEİ) ile işleme performansı üzerine etkilerinin gözlemlendiği bu çalışmada dielektrik sıvı içerine nano boyutta grafit tozu ilavesi ile başarılı ve kararlı işlemenin sağlanabileceği ve işleme performansının geliştirilebileceği düşünülmüştür. Bu amaçla \%5 B4C+\%5 SiC ve \%10 B4C+\%10 SiC takviye edilmiş Al7075 matrisli kompozitlerin EEİ'de boşalım akımı ve takviye oranlarının işlenen kompozitin yüzey yapısı üzerindeki rolü araştııılmıştır.

\section{Deneysel Çalışma}

Deneysel çalışmada kullanılan AA7075 matrisli B4C+SiC takviyeli hibrit kompozitler toz metalürjisi yöntemiyle \%5 B4C+\%5 $\mathrm{SiC}+\% 90 \mathrm{AA} 7075$ ve $\% 10 \mathrm{~B} 4 \mathrm{C}+\% 10 \mathrm{SiC}+\% 80 \mathrm{AA} 7075$ olmak üzere iki farklı takviye hacim oranında üretilmiştir. Kompozitlerin üretiminde $700 \mathrm{MPa}$ sıkıştırma basıncı, $550^{\circ} \mathrm{C}$ sinterleme sıcaklığı ve 150 dakika sinterleme süresi uygulanmıştır (Baydaroğlu 2018). Yaklaşık olarak $30 \mathrm{~mm}$ çapında ve $20 \mathrm{~mm}$ yüksekliğinde üretilmiş olan kompozit deney numunelerinin üretiminde kullanılan matris malzemesi AA7075 tozu ve takviye elamanları B4C ile SiC'e ait bazı teknik özellikleri gösteren değerler Tablo 1'de verilmiştir.

Tablo 1. Deney malzemelerinin teknik özellikleri

AA 7075'in özellikleri

\begin{tabular}{|c|c|c|c|c|c|c|c|}
\hline $\begin{array}{r}\% \mathrm{Fe} \\
0,50 \\
\end{array}$ & $\begin{array}{r}\% \mathrm{Si} \\
0,40 \\
\end{array}$ & $\begin{array}{l}\% \mathrm{Cu} \\
1,21-2,0\end{array}$ & $\begin{array}{r}\% \mathrm{Mn} \\
0,30 \\
\end{array}$ & $\begin{array}{l}\% \mathrm{Mg} \\
2,1-2,9\end{array}$ & $\begin{array}{l}\% \mathrm{Zn} \\
5,1-6,1 \\
\end{array}$ & $\begin{array}{r}\% \mathrm{Ti} \\
0,2 \\
\end{array}$ & $\begin{array}{c}\% \mathrm{Cr} \\
0,18-0,28\end{array}$ \\
\hline $\begin{array}{c}\text { Yoğunluk }(\mathrm{g} / \mathrm{cm} 3) \\
2,81\end{array}$ & \multicolumn{3}{|c|}{ Ergime noktas $1\left({ }^{\circ} \mathrm{C}\right)$} & \multicolumn{2}{|c|}{$\begin{array}{l}\text { Parçacık şekli } \\
\text { Yuvarlak }\end{array}$} & \multicolumn{2}{|c|}{ Isıl iletkenlik $\left(\mathrm{W} / \mathrm{mK} 20^{\circ} \mathrm{C}\right)$} \\
\hline \multirow{2}{*}{2,81} & \multicolumn{5}{|c|}{ B4C'nin özellikleri } & & \\
\hline & \multicolumn{3}{|r|}{$\begin{array}{c}\% \mathrm{~B} \\
78,28\end{array}$} & \multicolumn{2}{|l|}{$\% \mathrm{C}$} & & \\
\hline $\begin{array}{c}\text { Yoğunluk }(\mathrm{g} / \mathrm{cm} 3) \\
2,52\end{array}$ & \multicolumn{3}{|c|}{ Ergime noktas $1\left({ }^{\circ} \mathrm{C}\right)$} & \multicolumn{2}{|c|}{ Parçacık şekli } & \multicolumn{2}{|c|}{ Isıl iletkenlik (W/mK $\left.20^{\circ} \mathrm{C}\right)$} \\
\hline \multicolumn{8}{|c|}{ SiC’nin özellikleri } \\
\hline$\% \mathrm{Si}$ & $\% \mathrm{Al} 2 \mathrm{O} 3$ & \multicolumn{2}{|c|}{$\% \mathrm{Fe} 2 \mathrm{O} 3$} & $\% \mathrm{SiO} 2$ & $\% \mathrm{P} 2 \mathrm{O} 5$ & $\% \mathrm{SO} 3$ & $\% \mathrm{C}$ \\
\hline $61-66$ & $0,7-1,2$ & \multicolumn{2}{|c|}{$0,6-1,1$} & 0,02 & 0,07 & 0,3 & $22-26$ \\
\hline Yoğunluk (g/cm3) & \multicolumn{3}{|c|}{ Ergime noktas $1\left({ }^{\circ} \mathrm{C}\right)$} & \multicolumn{2}{|c|}{ Parçacık şekli } & \multicolumn{2}{|c|}{ Is1l iletkenlik (W/mK $\left.20^{\circ} \mathrm{C}\right)$} \\
\hline 3,21 & \multicolumn{3}{|c|}{2730} & \multicolumn{2}{|l|}{ Köşeli } & \multicolumn{2}{|c|}{$90-160$} \\
\hline
\end{tabular}


TKEEI deneylerinde $6 \mathrm{~mm}$ çapında grafit elektrot kullanılmıştır. Çubuk grafit formunda temin edilen grafit elektrotların takım tutucuya kolaylıkla bağlanabilmesi için Şekil 1'de gösterilen boy ve çap ölçülerine getirilmiştir. Grafit, elektriksel direncinin düşük olması ve üstün yüzey kalitesine olanak sağlaması nedeniyle tercih edilmiştir. Dielektrik sıvı olarak gaz yağı kullanılmıştır (Keskin 2019). Gaz yağı düşük viskozite ve yüksek püskürtme kalitesi özellikleri sunmaktadır (Kumar et al., 217). Dielektrik sıvı uygulaması yanal püskürtme biçiminde gerçekleştirilmiştir. Ayrıca deneylerde toz partikül büyüklüğü $50 \mathrm{~nm}$ den daha düşük olan nanografit tozu kulanılmıştır. EEİ deney parametreleri Tablo 2'de verilmektedir.

Tablo 2. TKEEI Deney Parametreleri

\begin{tabular}{ll}
\hline Boşalım Akımı (A) & $2,4,8$ \\
Vurum Süresi $(\mu \mathrm{s})$ & 8 \\
Bekleme Süresi $(\mu \mathrm{s})$ & 10 \\
Gerilim $(\mathrm{V})$ & $60-80$ \\
Kutuplama & Elektrot (-), İş parçası (+) \\
Elektrot Cinsi & Grafit \\
Dielektrik püskürtme & Yandan püskürtme \\
Toz katkısı ve derişimi & Grafit tozu (15 g/L) \\
\hline
\end{tabular}

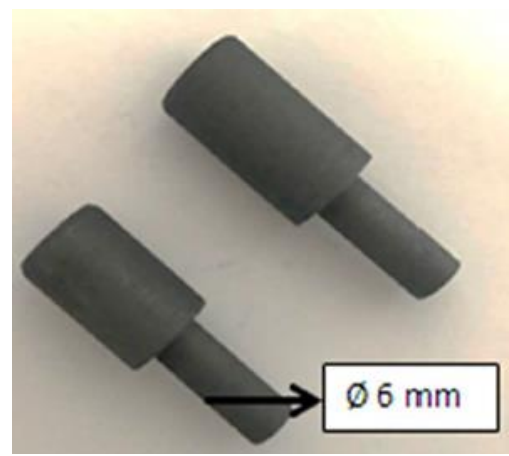

Şekil 1. Grafit elektrot (Keskin 2019)

EEİ deneyleri, Gazi Üniversitesi Teknoloji Fakültesi Laboratuvarı'nda bulunan Charmilles D20 marka elektro erozyon tezgâhında gerçekleştirilmiştir (Şekil 2).

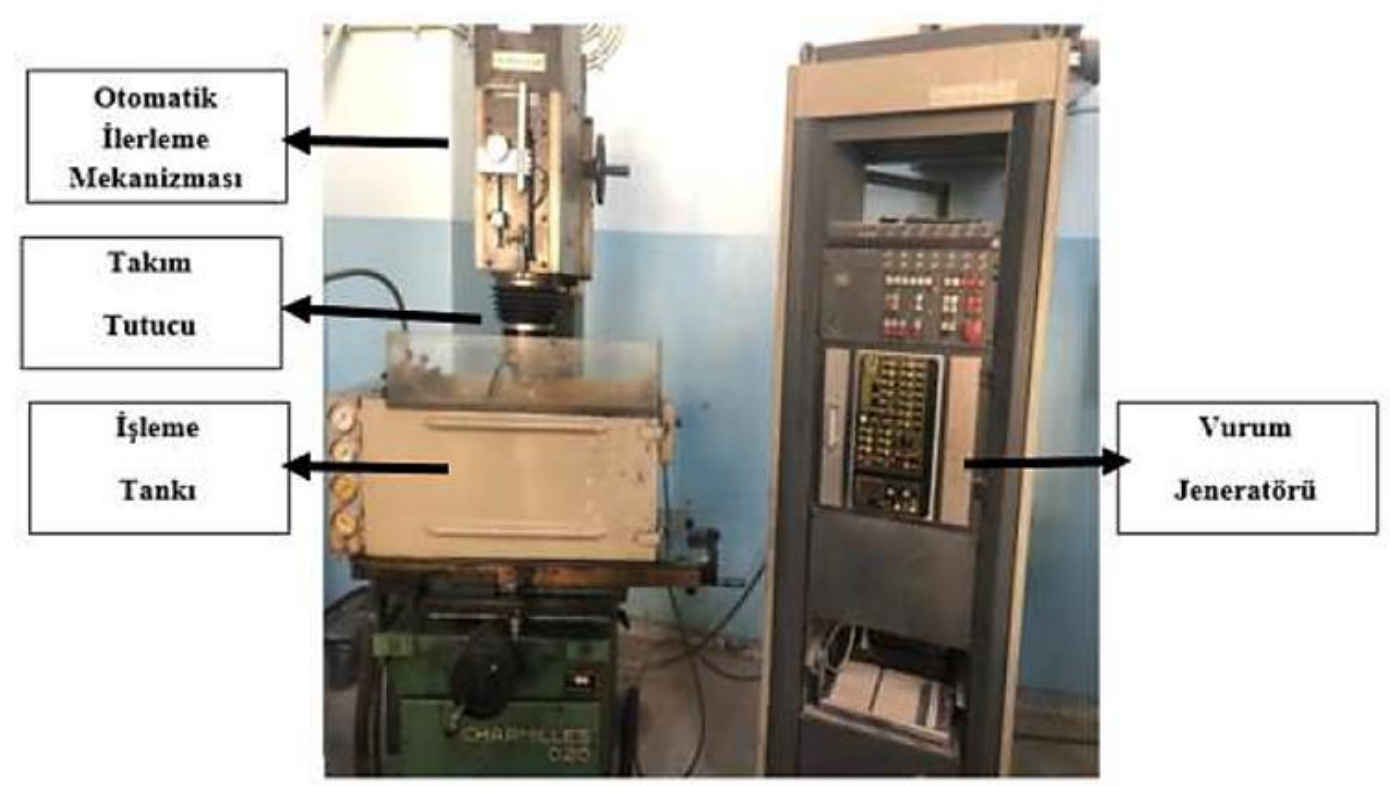

Şekil 2. EEİ deneylerinin yapıldığı tezgah (Keskin 2019) 
İş parçasını işleme derinliği sabit $2 \mathrm{~mm}$ olarak belirlenmiştir. Hedeflenen işleme derinliğine ulaşıldığında, otomatik olarak delik delme işlemi sonlandırılmıştır. Bu esnada işleme süresi kronometre ile tutulmuştur. Her bir delik delme işleminde ayrı grafit elektrot kullanılmıştır. İşleme deneyleri tamamlanan hibrit kompozit numunelerin Form Talysurf PGI marka ölçüm cihazı kullanılarak yüzey pürüzlüğ̈̈ ölçümleri yapılmıştır. Mikro yapı incelemesi ise Gazi Üniversitesi Teknoloji Fakültesi, Metalurji ve Malzeme Mühendisliği Bölümü SEM Laboratuvarı'nda bulunan taramalı elektron mikroskobu (SEM) ile gerçekleştirilmiştir. Ayrıca üretimi yapılan kompozit numunelerin Arşimet prensibi kullanılarak teorik yoğunluk değerleri ölçülerek porozite miktarları belirlenmiştir.

\section{Deney Sonuçları ve Tartışma}

\subsection{Mikroyapı İncelemesi}

İlk olarak kompozit yapıyı incelemek amacıyla toz metalürjisi yöntemiyle $\% 5$ B4C+\%5 SiC+\%90 AA7075 ve $\% 10$ B4C+\%10 $\mathrm{SiC}+\% 80$ AA7075 takviye hacim oranlarında üretilmiş olan kompozit deney numunelerinin mikroyapılarını gösteren SEM mikroskobu görüntüleri Şekil 3’te verilmiştir.
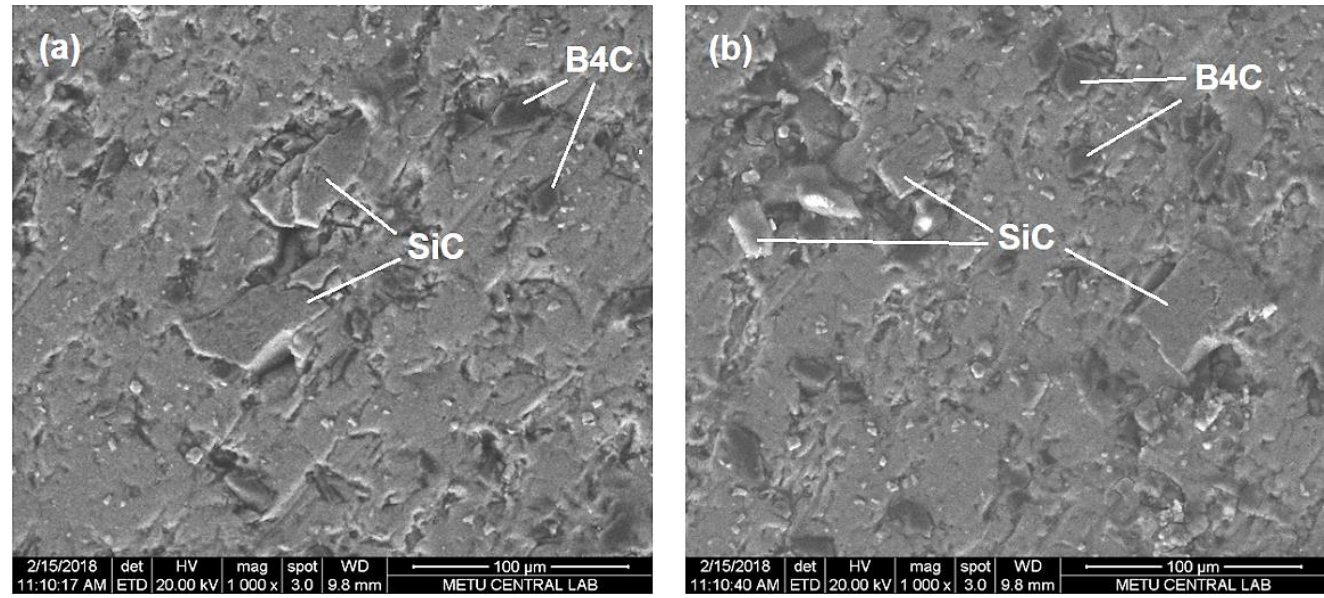

Şekil 3. a) \%5 B4C+\%5 SiC+\%90 AA7075 b)\%10 B4C+\%10 SiC+\%80 AA7075 (Baydaroğlu 2018)

Şekil 3'teki SEM görüntülerine bakıldığında, takviye elemanlarının homojen olmayan bir dağılım sergilediği görülmektedir. Ayrıca takviye parçacıklarının yer yer topaklandığı ve bu bölgelerin yanında gözeneklerin meydana geldiği görülmektedir. Arşimed prensibine göre ölçülen yoğunluk ve gözeneklilik değerleri Tablo 3’te verilmektedir.

Tablo3. SiC+B4C/A17075 kompozitlerde ölçülen yoğunluk ve gözeneklilik miktarları (Baydaroğlu 2018)

\begin{tabular}{l|c|c}
\hline \multicolumn{2}{c|}{$\% 5 \mathrm{SiC}+\% 5 \mathrm{~B} 4 \mathrm{C}$} & $\% 10 \mathrm{SiC}+\% 10 \mathrm{~B} 4 \mathrm{C}$ \\
\hline Yoğunluk (\%) & 94,52 & 90,24 \\
Gözeneklilik $(\%)$ & 5,48 & 9,76 \\
\hline
\end{tabular}

Takviye topaklanmasının olduğu bölgelerde matris malzemesi AA7075 ile takviye elemanları B4C ve SiC arasında yeterli seviyede ıslatmanın olamadığı ve matris-takviye ara yüzeylerindeki bağlanmanın zayıf veya hiç olmadığı anlaşılmaktadır. Yukarıda zikredilen olumsuz mikroyapı özellikleri, bu tür kompozit yapılarda sıklıkla karşılaşılan ve literatürde yer alan bir sonuçtur (Pul ve Baydaroğlu 2020; Pul 2018).

Toz metalurjisi tekniği ile üretilen $\mathrm{SiC}+\mathrm{B} 4 \mathrm{C}$ parçacık takviyeli Al7075 matrisli kompozit deney numunelerinin grafit elektrot ile 2A, 4A ve $8 \mathrm{~A}$ boşalım akımlarında TKEEİ yöntemiyle işlenmesinden sonra elde edilen kör delikler ve deney numunelerinin genel görünüşleri Şekil 4'te verilmiştir.
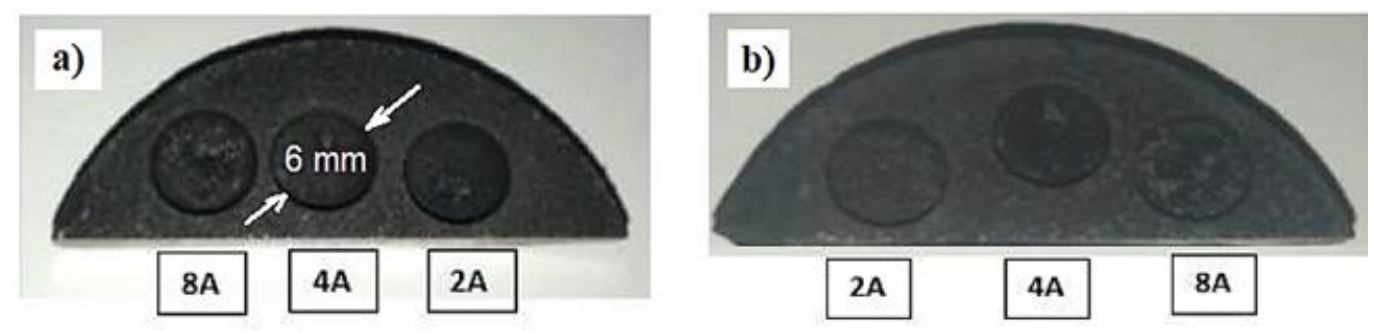

Şekil 4. a) $\% 5 \mathrm{~B} 4 \mathrm{C}+\% 5 \mathrm{SiC}+\% 10 \mathrm{AA} 7075$ deney numunesi, b) $\% 10 \mathrm{~B} 4 \mathrm{C}+\% 10 \mathrm{SiC}+\% 10 \mathrm{AA} 7075$ deney numunesi (Keskin 2019) 
İşleme deneyleri tamamlandıktan sonra, \%5 SiC+\%5 B4C ve \%10 SiC+\%10 B4C takviyeli AA7075 kompozit malzemelerin işlenmiş yüzeylerinden çekilen 100x büyütmedeki SEM görüntüleri Şekil 5'te toplu olarak gösterilmektedir.

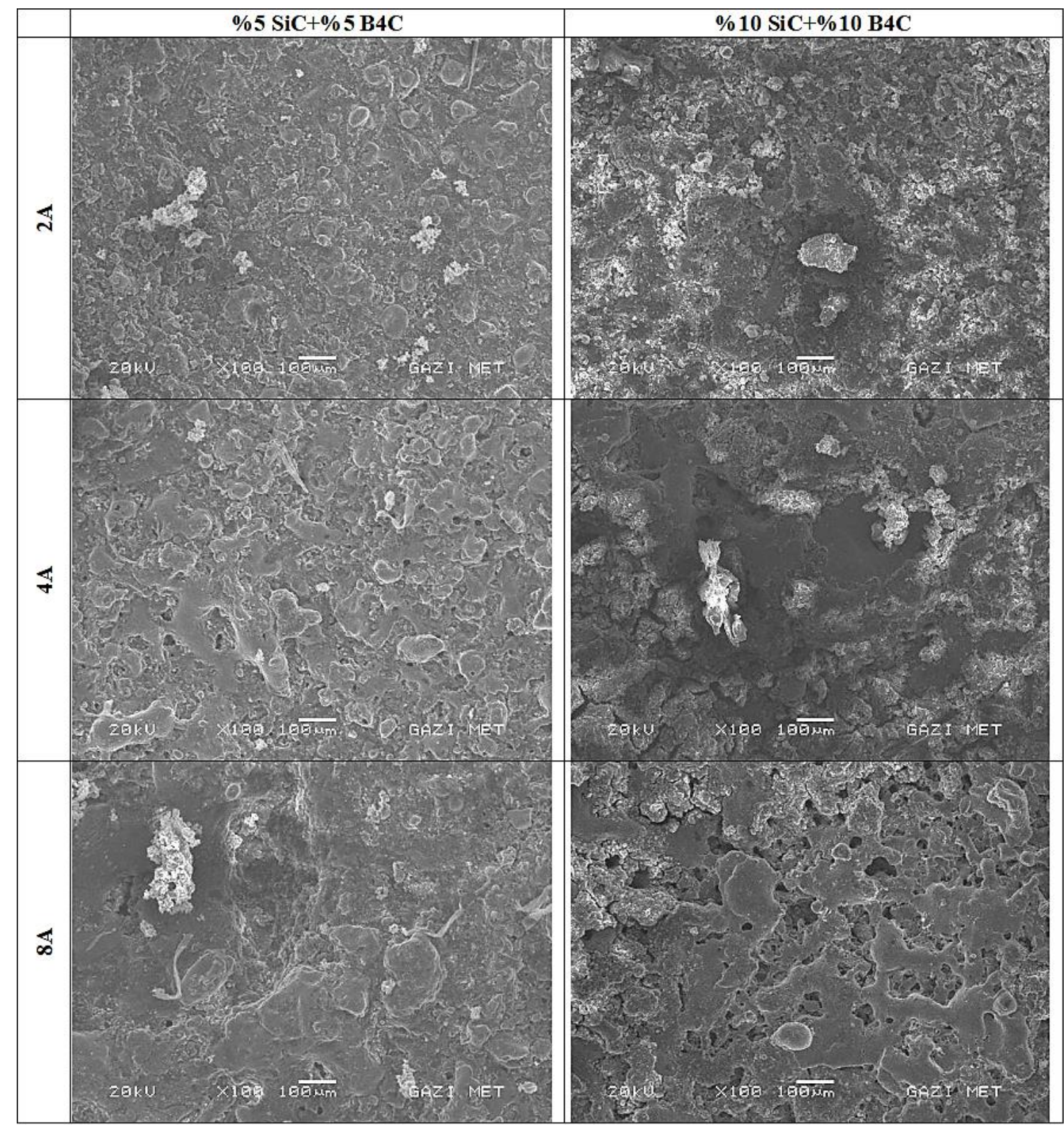

Şekil 5. \%5 SiC+\%5 B4C ve \%10 SiC+\%10 B4C takviyeli AA7075 kompozitlerin SEM görüntüleri (Keskin 2019)

EEİ işleme operasyonlarında boşalım akımının artmasıyla oluşan yüzey hasarlarının da artması beklenir. Akım şiddetinin artması, iş parçası yüzeyine daha yoğun bir enerji boşalımın olmasına yol açmakta ve bunun sonucu olarak yüzeyden daha fazla talaş kaldırılmaktadır (Keskin 2019). Şekil 5'teki SEM görüntülerine bakıldığında, boşalım akınının 2A'den 8A'e çıkmasıyla işlenmiş yüzeylerdeki deformasyonunda arttı̆̆ görülebilmektedir. Bu deformasyon hem parçacık kopması hem de malzemenin erimiş halde bir görüntü sergilemesiyle karşımıza çıkmaktadır. Şekil 5 'te yer alan her iki kompozit malzemenin de 8A ile işlemiş̧ yüzey görüntülerinde, erimiş malzeme bölgeleri çok bariz olarak görülmektedir. Ayrıca, yüzeyden kaldırılan talaş miktarının artması, aynı zamanda yüzey pürüzlülüğünü de olumsuz yönde etkileyebileceği düşünülebilir.

Şekil 5'teki SEM görüntülerine toplu olarak bakıldı̆̆ında, \%SiC+\%B4C oranının artmasıyla yüzey mikro yapısının daha gözenekli hale gelmiş olduğu da anlaşılmaktadır. İşleme sırasında AA7075 matris içerisine gömülü haldeki $\mathrm{SiC}$ ve B4C takviye parçacıkları koparak uzaklaşmıştır. Doğal olarak \%10 SiC+\%10 B4C takviyeli numuneden $\% 5 \mathrm{SiC}+\% 5 \mathrm{~B} 4 \mathrm{C}$ takviyeli numuneye göre daha fazla takviye parçacığı kopmuştur. Kopan takviye parçacıklarını yeri boşluk olarak karşımıza çıkmaktadır. Aynı zamanda yüksek takviye oranında daha fazla takviye topaklanması meydana geldiği daha önce ifade edilmişti. Topaklanmış bölgelerde yoğun ve bir arada bulunan takviye parçacıklarının büyük kütleler halinde kompozit yapıdan uzaklaştığı anlaşılmaktadır. Nitekim Şekil 5’teki 4A boşalım 
akımında işlenmiş olan \%10 SiC+\%10 B4C takviyeli numunenin SEM görüntüsüne bakıldığında büyük bir gözeneğin oluştuğu görülmektedir.

\subsection{Yüzey pürüzlülüğünün incelenmesi}

Tablo 4'te \%5 SiC+ \%5 B4C ve \%10 SiC+ \%10 B4C takviyeli AA7075 kompozitlerin yüzey pürüzlülügü değerleri, Şekil 6'da ise pürüzlülük değerlerine göre çizilen grafik verilmektedir.

Tablo 4. SiC+B4C/Al7075 kompozitlerde ölçülen ortalama yüzey pürüzlülük değerleri

\begin{tabular}{l|ccc|ccc}
\hline \multicolumn{3}{c|}{$\% 5 \mathrm{SiC}+\% 5 \mathrm{~B} 4 \mathrm{C}$} & \multicolumn{3}{c}{$\% 10 \mathrm{SiC}+\% 10 \mathrm{~B} 4 \mathrm{C}$} \\
\hline $\operatorname{Ak} 1 \mathrm{~A}(\mathrm{~A})$ & $2 \mathrm{~A}$ & $4 \mathrm{~A}$ & $8 \mathrm{~A}$ & $2 \mathrm{~A}$ & $4 \mathrm{~A}$ & $8 \mathrm{~A}$ \\
$\operatorname{Ra}(\mu \mathrm{m})$ & 5,00 & 6,17 & 7,00 & 5,53 & 6,39 & 7,04 \\
\hline
\end{tabular}

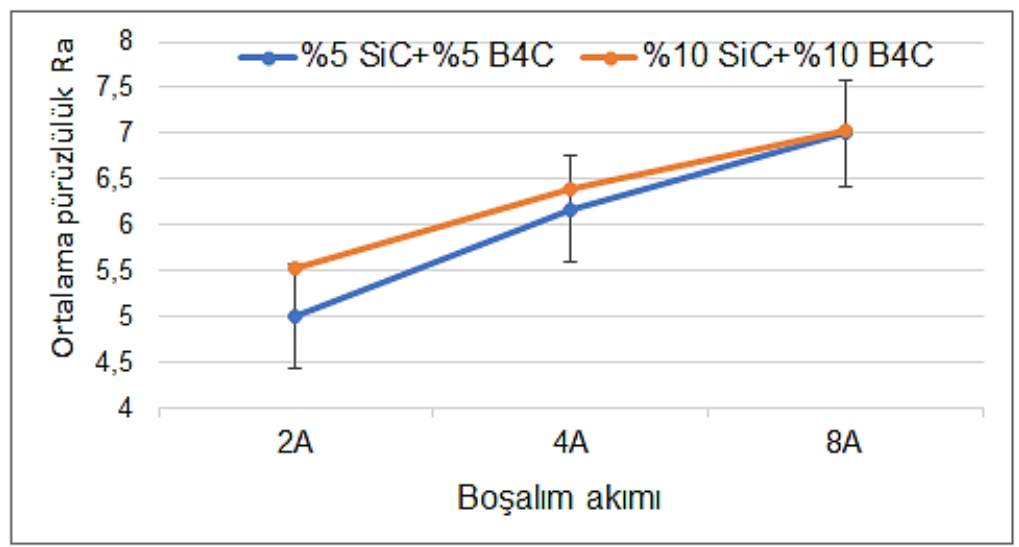

Şekil 6. SiC+B4C takviyeli kompozitlerde boşalım akımının Ra değerine etkisi

Ölçümler sonucunda elde edilen en yüksek pürüzlülük değeri 8A boşalım akımında işlenen \%10 SiC+\%10 B4C takviyeli kompozitte $7,04 \mu \mathrm{m}$ olarak ölçülürken, en düşük pürüzlülük değeri $2 \mathrm{~A}$ boşalım akımında işlenen $\% 5 \mathrm{SiC}+\% 5 \mathrm{~B} 4 \mathrm{C}$ takviyeli kompozitte $5,00 \mu \mathrm{m}$ ölçülmüsştür. Bu genel sonuca göre, boşalım akımının ve $\mathrm{SiC}+\mathrm{B} 4 \mathrm{C}$ takviye oranının yükselmesiyle yüzey pürüzlülük değerlerinin de yükselmiş olduğu sonucu ortaya çıkmaktadır.

Kompozit malzemeler kendi içinde değerlendirildiğinde ise, \%10 SiC+\%10 B4C takviyeli kompozitlerin, \%5 SiC+\%5 B4C takviyeli kompozitlere kıyasla yüzey pürüzlülüğü aralığının daha düşük olduğu görülmektedir. Dikkat çeken diğer husus ise boşalım akımı değeri yükseldikçe her iki kompozit malzemeden elde edilen pürüzlülük değerlerinin biri birine yaklaşıyor olmasıdır. Hatta 8A boşalım akımında neredeyse aynı pürüzlülük değeri elde edilmiştir.

TKEEİ yönteminin esası gereği boşalım akımının artmasına bağlı olarak, ergime esnasında iş parçası ile elektrot arasında yüksek sıcaklık meydana gelir ve malzemeler ve 1sı dielektrik sıvı ile kolayca uzaklaştırılamaktadır. Rastgele tekrarlı ve düzenli devam eden boşalımlar sonrası metal malzemelerin işlenmesinde, parça yüzeyinde kratersi bir yapı oluşumuna sebep olur. EEİ ilenmesinde, boşalım akımı arttıkça daha geniş ve derin kraterler oluşması işlemin doğal bir sonucu olarak kabul edililir. Ancak ısıl iletkenliği ve elektriksel iletkenliği düşük seramik ve seramik takviyeli metal matrisli malzemelerin TKEEİ ile işlenmesinde durum biraz daha farklıdır. Elde edilen SEM fotoğraflarında yüzey görüntülerinin metal bir malzemedeki gibi yüzeyde kratersi görüntüden çok düzensiz katman şeklinde katılaşma görüntüleri elde edilmiştir. Akım değerinin atması ile bu düzensizliklerin arttığı görülmektedir. Toz takviyesi ile kararlı boşalımlar ile işlemenin devamı sağlanmış ancak boşalım düzensizlikleri sonucu oluşan kalıntı ısının atılamaması ile ergiyik malzemenin kontrolsüz bir şekilde yüzeye yeniden bağlanması sonucu katman katman düzensiz katılaşmalar oluşmuştur (Şekil 5). Ölçümler sırasında yüzey pürüzlülük cihazının hareketli probunun bu farklı derinliklere sahip düzensiz girinti ve çıkıntılara girip çıkması söz konusudur. Dolayısıyla oluşan kraterlerin büyüklüğü ve derinliği yüzey pürüzlülüğünü etkileyen en önemli sebeptir. Sonuç olarak bu kompozit malzemelerle yapılan çalışmada yüzey pürüzlülüğü üzerinde, boşalım akımının etkisinin takviye oranının etkisinden daha fazla ön plana çıktığı söylenebilir. Benzer sonuç literatürdeki bir çalışmada yer almaktadır (Kumar ve Davim 2011).

\section{Sonuçlar}

$\% 5 \mathrm{SiC}+\% 5 \mathrm{~B} 4 \mathrm{C}$ ve $\% 10 \mathrm{SiC}+\% 10 \mathrm{~B} 4 \mathrm{C}$ hibrit kompozit malzemeler, toz metalurjisi ile başarılı bir şekilde üretilmiştir. TKEEI kullanarak iki tip hibrit alüminyum metal matris kompozitlerin işlenebilirliğini farklı akım parametreleri ile yüzey karakteristiklerine etkisini incelenmiştir. Deneysel verilerle aşağıdaki sonuçlar çıkarılmıştır:

Takviye/hacim oranı yüksek hibrit kompozit malzemelerin işlenmesinde bile kararlı bir işleme rejimi olması dielektrik sıvı içerisine nano boyutlu grafit tozlarının ilavesiyle mümkün olabilmiştir. İşlenen yüzey görüntülerinin metal bir malzemeyi işleme sonrası elde 
edilen kratersi görüntüden çok düzensiz katman şeklinde katılaşma görüntüleri elde edilmiştir. Akım değerinin atması ile bu düzensizliklerin arttığı görülmektedir. Her ne kadar nano grafit takviyesi ile işlemenin sürekliliği sağlanmış ise de elektriksel iletken olmayan takviye malzemenin etkisiyle oluşan boşalım düzensizlikleri oluşmuş yüzeydeki kalıntı ısının atılamaması sonucu ergiyik atık malzeme dielektrik sıvı ile kolayca uzaklaştırılamış ve yüzeyde düzensiz katılaşmalar formlanmıştır. Darbe akımındaki artış, boşalım enerjisini arttırdığı için düzensiz katılaşma daha da artmıştır. Bu da yüzey pürüzlüğünde takviye hacim oranındaki artışın etkisinden daha çok akım değerindeki artışın neden olumsuz bir sonuç doğurduğunu açıklamaktadır.

\section{Referanslar}

Baydaroğlu, V. (2018). Balistik Malzeme Üretimine Yönelik B4C + SiC Takviyeli Al 7075 Kompozitlerde Optimum Katkı Oranının Belirlenmesi. Yüksek Lisans Tezi, Kırıkkale Üniversitesi Fen Bilimleri Enstitüsü, Kırıkkale, 30-101.

Garg, R. K., Singh, K. K., Sachdeva, A., Sharma, V.S., Ojha, K. and Singh, S. (2010). Review of research work in sinking EDM and WEDM on metal matrix composite materials. International Journal Advanced Manufacturing Technol, 50, 611-624. doi: $10.1007 / \mathrm{s} 00170-010-2534-5$

Karakoç, H. (2017). TM Yöntemi ile B4C Takviyeli AA6061 Metal Matrisli Kompozit Malzemelerin Üretimi, Mekanik Özelliklerinin ve Balistik Performansının İncelenmesi. Doktora Tezi, Gazi Üniversitesi Fen Bilimleri Enstitüsü, Ankara, 15-36.

Keskin, G. (2019) SiC, B4C ile Takviyelendirilmiş Al7075 Alaşımının Toz Katkılı Elektro Erozyon İle İşlenmesinde İşleme Parametre Etkilerinin Deneysel Olarak İncelenmesi. Yüksek Lisans Tezi, Gazi Üniversitesi Fen Bilimleri Enstitüsü, Ankara, 1-107.

Kolli, M. and Kumar, A. (2015) Effect of dielectric fluid with surfactant and graphite powder on Electrical Discharge Machining of titanium alloy using Taguchi method. Engineering Science and Technology, an International Journal, 18, 524-535.

Kumar, H. and Davim, J.P. (2011). Role of powder in the machining of Al-10\%SiCp metal matrix composites by powder mixed dielectric discharge machining. Journal of Composite Materials, 45(2), 133-151. doi:10.1177/0021998310371543

Kumar, D., Kumar, K., Payal, H.S., Mer, K.K.S. (2017). A state-of-the-art review ondielectric fluid in electric discharge machining: uses and its effects. International Research Journal of Engineering and Technology, 4(7), 1185-1190.

Mardi, K.B., Dixit, A.R. and Mallick, A. (2017). Studies on non-traditional machining of metal matrix composites. Materials Today: Proceedings, 4, 8226-8239. doi:10.1016/j.matpr.2017.07.165

Mohanty, S., Singh, S.S., Routara, B.C., Nanda, B. K., Nayak, R.K. (2019) Comparative study on machining of AlSiCp metal matrix composite using Electrical discharge machine with and without nano powder suspension in dielectric. Materials Today: Proceedings, $18,4281-4289$.

Sezen, G. (2018). Metal Matrisli Kompozit Malzemelerde Takviye Malzemesinin Yüzey Özelliklerinin İyileştirilmesi. Yüksek Lisans Tezi, Yıldız Teknik Üniversitesi Fen Bilimleri Enstitüsü, İstanbul, 6-14.

Sidhu, S.S., Ajay Batish, A., Kumar, S. (2014) Study of Surface Properties in Particulate-Reinforced Metal Matrix Composites (MMCs) Using Powder-Mixed Electrical Discharge Machining (EDM). Materials and Manufacturing Processes, 29, 46-52. doi: $10.1080 / 10426914.2013 .852211$

Pul, M., Baydaroğlu, V. (2020) B4C/SiC katkılı alüminyum esaslı kompozitlerin mekanik özelliklerin incelenmesi ve balistik performanslarının modellenmesi. Politeknik Dergisi, 23(2), 382-392.

Pul, M (2018) Effect of B4C Reinforcement Ratio and Sintering Temperature on the Mechanical Behavior in Al-B4C Composites, Science of Sintering, 50(1), 51-61. 